\title{
Pequenas e Médias Empresas no Contexto da Gestão da Qualidade Total
}

\author{
José Carlos Teixeira da Silva, Doutor em Engenharia (Poli-USP) \\ Prof. Doutor / Faculdade Engenharia / Depto. Eng. de Produçãol UNESP \\ Av. Luiz Edmundo C. Coube AS/N CEP 17033-000, Bauru-SP \\ Dorival Ferreira, Doutor em Educação (Unesp) \\ Prof. Doutor / Faculdade Engenharia / Depto. Eng. de Produção/ UNESP \\ Av. Luiz Edmundo C. Coube AS/N CEP 17033-000, Bauru-SP
}

\section{Resumo}

Este trabalho analisa a gestāo da qualidade em organizaçōes, envolvendo pequenas e médias empresas do setor de manufaturados, utilizando um modelo conceitual que envolve aspectos estratégicos e operacionais da gestāo da qualidade. Através de referências bibliográficas e pesquisa de campo encaminha uma análise da gestāo da qualidade nessas organizaçōes, concluindo que existem dificuldades nesse campo. Existe indicaçāo da necessidade de desenvolvimento de procedimentos e metodologias específicas para essa categoria de organizaçāo.

Palavras-chave: qualidade, qualidade de análise de gerência, SMEs

\section{Abstract}

This paper discusses the quality management in organizations with respect the strategic and operational aspects, and analyses the stage of traditional small and medium enterprises-SMEs of the manufacture sector, with support of bibliographical references and exploratory research. It was detected some aspects concerning the quality management for those companies: absence of global strategic planning and no practices in conventional tools of quality at factory level. Because any regional and cultural characteristics, those firms still get to survive, at short term. However, we denote the necessary introduction of specifics methodologies in quality management for those enterprises.

Keywords: quality, quality management analysis, SMEs

\section{Introdução}

Pode-se dizer que a preocupação com a qualidade dos produtos teve origem com o surgimento da produção em maior escala, no início do século passado, onde se constata o início da era da inspeção formal, segundo Garvin (1992), a qual foi motivada pelo Departamento de Material Bélico do E. U. A.. Durante aquela fase algumas melhorias foram introduzidas. Como o uso de sistemas de medidas, padrões e gabaritos, mas somente um século depois, com a introdução da administração científica de Taylor (1911), é que a quali- dade foi reconhecida como área funcional dentro do gerenciamento de uma.empresa, de acordo com a obra de Radford intitulada The Control of Quality in Manufacturing. As fases seguintes envolveram inicialmente a introdução de controle estatístico, com os trabalhos de Shewhart (1931) e com aquilo que se denominou nivel de qualidade aceitável, conceito oriundo dos trabalhos de Harol Dodge e Harry Romig (1944), da Bell Laboratories. No final da década de 50 constata-se direcionamento para a era da garantia da qualidade, com implicações mais amplas para o gerenciamento e envolvendo vários aspectos: 
PRODUÇÃO

quantificação dos custos da qualidade e da não qualidade, com Joseph Juran (1951), controle total da qualidade, com Armand Feigenbaum (1956), engenharia da confiabilidade através de modos e efeito de falhas, e defeito zero com os trabalhos de James Halpin (1956) e Philip Crosby (1956) na Martins Company, cujos fundamentos alteraram a ética da qualidade até então dominante do chamado nivel de qualidade aceitável, sendo o último movimento importante da era da garantia da qualidade. Durante a década de 1950, Edwards Deming introduziu, através da JUSEJapan Union of Scientists and Engineers, vários conceitos de gestão da qualidade, como o controle estatistico de processo, $a$ relação entre qualidade e produtividade, o ciclo Deming PDCA, e outros, dentro do que mais tarde foi denominado de Os Quatorze Pontos Básicos de Deming, como se pode constatar pela obra de Howard Gitlow (1987) "The Deming Guide To Quality and Competitive Position". Outras contribuições importantes vieram com os trabalhos de Juran e Feigenbaum nas áreas gerencial e de qualidade total, com direcionamento para os chamados círculos de qualidade, e posteriormente para o controle da qualidade total (CWQC-Company Wide Quality Control), e para a gestão da qualidade total (TQM - Total Quality Management), formas organizacionais essas que caracterizaram as grandes industrias japonesas e seus inúmeros fornecedores nas décadas de 60 e 70 , sendo posteriormente difundidas para outros países com algumas adaptações, caracterizando-se de acordo com a classificação de Merli (1994) como organizações "market-in" (empreendimento) ou empresas de classe mundial. Essas formas organizacionais emergentes, como alternativa à teoria Taylorista, embora sem um total rompimento com esta, se concentram na maioria das vezes em grandes empresas, e envolvem aspectos de planejamento estratégico e operacional, a curto, médio e longo prazos, de caracter sistêmico, incorporando o cliente-fornecedor dentro daquilo que se denominou chamar de cadeia de valor, utilizando as técnicas de "comakership", como relata Merli(1994).

A evolução da gestão da qualidade nas empresas japonesas, a partir da década de 60 , foi conduzida partindo do "chão de fábrica" e posteriormente envolvendo outros setores das empresas, seu meio ambiente interno e externo. Na realidade, todo esse trabalho foi conduzido operacionalmente, ou seja, através de ensaios e aplicação prática, sem preocupação de desenvolvimento de teorias acadêmicas. Somente mais tarde começaram a aparecer algumas publicações japonesas, porém específicas. A adaptação das empresas americanas à essa forma organizacional alternativa gerou no meio acadêmico americano, principalmente na Harvard University e no M.I.T., esforços para explicar o que estava ocorrendo com as empresas japonesas, com direcionamento para várias teorias no campo da gestão da qualidade. Essas teorias têm sido divulgadas em todo o mundo, interligando a globalização da economia com a forma organizacional das empresas, porém de difícil aplicabilidade nas organizações, mesmo para grandes empresas, e muito mais para pequenas e médias empresas.

A transposição dessa teoria para pequenas e médias empresas tem sido problemática, independentemente de região geográfica, pois envolve além da sua adequação para organizações de menor porte, outros aspectos peculiares e regionalizados, entre eles o cultural.

Este trabalho analisa, a partir de alguns conceitos dessa teoria, a situação atual de pequenas e médias empresas tradicionais, do setor de manufaturados, no campo da gestão da qualidade, procurando conhecer o estágio dessas organizações dentro do contexto presente da chamada economia globalizada. Pretende-se, a partir de um modelo conceitual simplificado, fundamentado em referenciais bibliográficos, e de informações de pesquisa de campo, delinear alguns aspectos importantes do comportamento dessas organizações na área da gestão da qualidade. 


\section{Conceituação e Metodologia}

Para a abordagem do trabalho foram utilizados alguns conceitos, tanto no que se refere às características das empresas, como no campo da gestão da qualidade. Assim, as organizações analisadas envolvem empresas tradicionais de função principal manufatura, entre elas as pequenas empresas-PE (20 a 100 funcionários) e as médias empresas-ME (100 a 500 funcionários). Para efeito de análise, as denomidadas grandes empresas não estão incluídas diretamente neste trabalho, exceto no que se refere à teoria moderna da gestão da qualidade, que foi desenvolvida e tem presença marcante nesse tipo de organização.

A conceituação inerente à gestão da qualidade envolve o modelo conceitual simplificado, de acordo com a Figura 1, relacionando alguns aspectos das "dimensões estratégica e operacional" da gestão da qualidade com a "dimensão empresas", esta última não significando ordem de grandeza. qualidade nas PE e ME com aqueles correlacionados à filosofia da teoria geral da gestão da qualidade. Analogamente, os aspectos da "dimensão operacional" estão relacionados à prática de técnicas e procedimentos básicos para a gestão da qualidade nessas organizações.

A metodologia utilizada, no do campo da pesquisa organizacional, se concentra em abordagem qualitativa, caracterizando-se como projeto de pesquisa o levantamento de dados e como método o "questionário auto-administrado", de acordo com a concepção de Bryman (1989).

Desta forma, a discussão de aspectos relacionados às "dimensões" foi conduzida com base em referências bibliográficas no que se refere à teoria moderna da gestão da qualidade, e na pesquisa de campo em pequenas e médias empresas conduzida por Silva (1999). Pode-se dizer que a maioria das referências bibliográficas de trabalhos de pesquisa, no campo da gestão da qualidade, é orientada para as grandes empresas, sendo limitadas aquelas relacionadas às pequenas e médias empresas, como os trabalhos de Ghobadian;

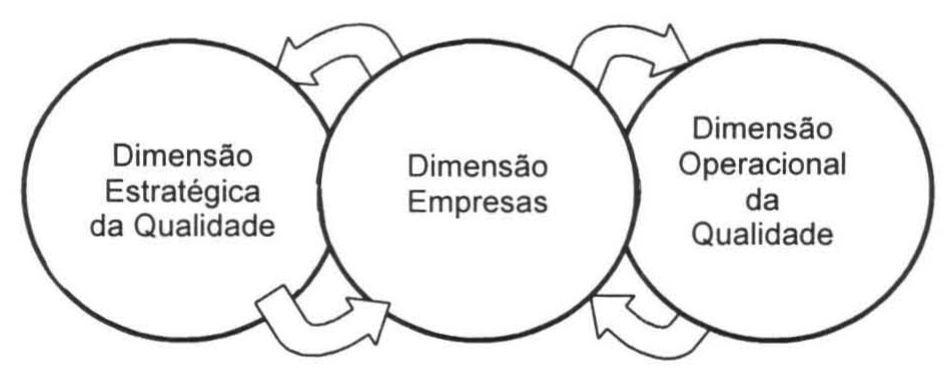

Figura 1- Modelo Conceitual para Análise da Gestão da Qualidade em Empresas

O Quadro 1 indica aspectos correlacionados às dimensões estratégica e operacional. Os aspectos da "dimensão estratégica" da gestão da qualidade são dependentes, entre outros, da configuração de planejamento estratégico da empresa, ou seja, de estarem incluídos dentro desse planejamento a curto, médio e longo prazo, visando comparar alguns aspectos da gestão da
Gallear (1996) e Parkin; Parkin (1996). No que se refere ao levantamento de dados, objetivando analisar o comportamento dessas organizações, cujo detalhamento pode ser consultado em Silva (1999), foi conduzido através de amostragem intencional em empresas associadas ao CIESP- Centro das Indústrias do Estado de São Paulo, distribuídas por 27 cidades, entre capital e interior, 


\begin{tabular}{||ll||}
\hline \multicolumn{1}{|c|}{ Aspectos Correlacionados à Dimensão Estratégica da Qualidade } \\
\hline \hline & prática da planejamento estratégico a curto, médio e longo prazos, na empresa \\
\hline & avaliação das expectativas dos clientes \\
centralização ou não na definição das metas globais e objetivos da empresa \\
conhecimento das metas e objetivos da empresa pelos funcionários \\
interesse da alta administração da empresa por estudos de gestão organizacional \\
$\square$ & conhecimento dos concorrentes em nivel nacional e internacional \\
$\square$ & dependência como fornecedor ou não de grandes empresas \\
$\square$ & auto-avaliação de seus produtos em relação aos da concorrência \\
$\square$ & gerenciamento por objetivos contraria a filosofia da gestão da qualidade total \\
\hline \hline & \multicolumn{1}{c|}{ Aspectos Correlacionados à Dimensão Operacional da Qualidade } \\
\hline$\square$ & comunicação entre os funcionários da empresa \\
$\square$ & treinamento e educação para a qualidade \\
$\square$ & utilização de controle estatístico de processo \\
$\square$ & certificação ISO 9000 como exigência de clientes \\
$\square$ & tipo de produção (pequenos lotes, em massa, processo contínuo, fragmentação) existente na empresa \\
$\square$ & confiança da alta administração nos funcionários \\
$\square$ & conhecimento dos conceitos de custos de produção e custo da qualidade \\
$\square$ & mercado atuante, nacional ou internacional \\
$\square$ & assistência técnica pós-venda \\
$\square$ & canais de distribuição dos produtos \\
\hline \hline
\end{tabular}

\section{Quadro 1 - Aspectos Correlacionados às Dimensões Estratégica e Operacional}

resultando em retorno de questionários aproveitáveis de 50 pequenas empresas e 40 médias empresas, relacionadas na Tabela 1 do Anexo 1. O questionário auto-administrado envolve questões que enfocam alguns dados gerais das empresas, e se concentra em aspectos correlacionados à teoria da gestão da qualidade, no que se refere ao comportamento dessas organizações, utilizando escalas de avaliação no campo da estatística não-paramétrica. Os dados em escalas nominais, dicotômicos ou de vários postos, são analisados através de teste de aleatoriedade, teste $\mathrm{c}^{2}$, e histogramas, visando o delineamento de tendências para a população. Similarmente, os dados em escalas ordinais, utilizando escalas tipo Likert (1935 ) apud Hayes (1992), são analisados através de teste de normalidade, calculo da mediana e intervalos de confiança da mediana. De acordo com Siegel (1975), na hipótese de uma amostra para cada categoria de empresas, como na presente pesquisa, a estatística mais adequada para a escala nominal é a frequência, enquanto que a indicação de tendência central de uma escala ordinal é a mediana, pois "na escala ordinal geralmente os intervalos sucessivos (distância entre classes) são diferentes, o que significa que não é adequada a utilização da média ou desvio padrão para tomada de decisões sobre hipóteses ou tendências". A análise dos dados pode ser consulta em Silva (1999).

\section{Análise da Pesquisa de Campo para "PE" e "ME"}

Os aspectos gerais das empresas pesquisadas, apresentados na Figura 2 indicam informações básicas dessas organizações. A maioria das empresas, com as $\mathrm{ME}$ originárias das décadas 70 e 80 , e as PE do período 85 a 90 , atuam predominantemente no mercado nacional (ao redor de 90\%), com algumas atividades de exportação para $50 \%$ das ME e $15 \%$ das PE. Constata-se que somente $50 \%$ das ME e $12 \%$ das PE dispõem de endereço eletrônico, implicando em dificuldades dessas empresas para acesso às redes informatizadas de dados e comunicação Ao serem indagadas sobre o interesse da alta administração dessas empresas, em estudo de teorias organizacionais, constatase que $80 \%$ das ME e $50 \%$ das PE responderam positivamente, indicando que nessas organizações já existe algum 
interesse nesse campo. Os dados indicam que a maioria dessas empresas ( $75 \%$ das PE e $90 \%$ das ME) se caracterizam parcialmente como fornecedoras de grandes empresas, significando uma dependência de mercado. No que se refere ao tipo de produção, $52 \%$ das $\mathrm{ME}$ operam através de plataformas, padronizações e em série, e $48 \%$ através de pequenos lotes. Em $75 \%$ das PE prevalece a produção em pequenos lotes, e as outras $25 \%$ utilizam operação em série, por plataformas ou padronizações. entre elas, a dimensão de mercado para seus produtos. $\mathrm{Na}$ realidade, as dificuldades atuais dessas organizações parecem advindas mais da adaptação à estabilização da economia do que propriamente da concorrência internacional. Ao indagar outros aspectos de produto/ mercado, a maior parte das empresas (ao redor de 75\%) indicou o preço como o ponto forte da concorrência e a qualidade como ponto forte de seus produtos (ao redor de $90 \%$ ), aspectos esses que abordaremos posteriormente.

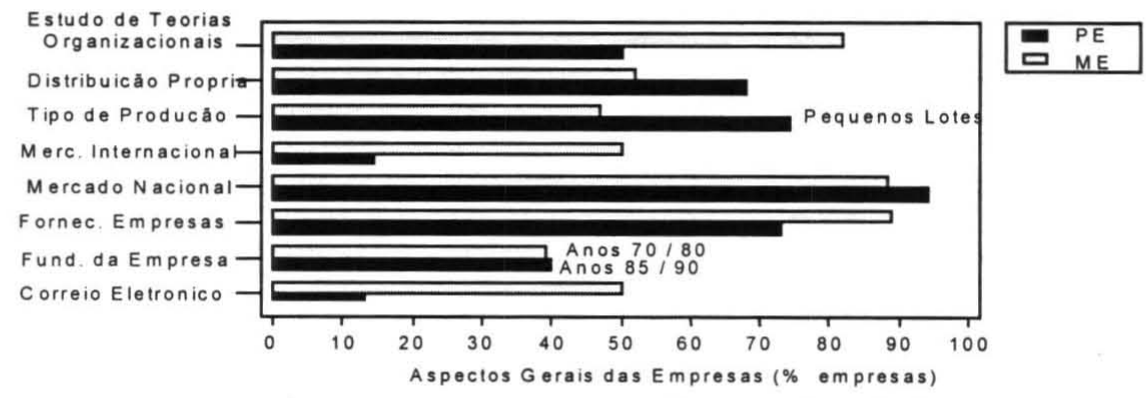

Figura 2 - Aspectos Gerais das Empresas Pesquisadas

Com relação aos aspectos de produto/mercado a Figura 3 indica que a maior concorrência para as PE e ME origina-se no mercado nacional. Por outro lado, a concorrência internacional é relevante para $35 \%$ das ME e $27 \%$ das PE. Essa constatação traz a indicação de que a maior parte das PMEs, por aspectos regionais e culturais, ainda não foram afetadas por algumas características da chamada economia globalizada,
Essa constatação indica que os conceitos relacionados à gestão da qualidade ainda não foram absorvidos por essas organizações, as quais operam ainda com características da era da inspeção e da garantia da qualidade, ou seja, concentração somente em qualidade de conformação a altos custos de produção.

O comportamento das empresas, em aspectos correlacionados às dimensões estratégicas e operacionais

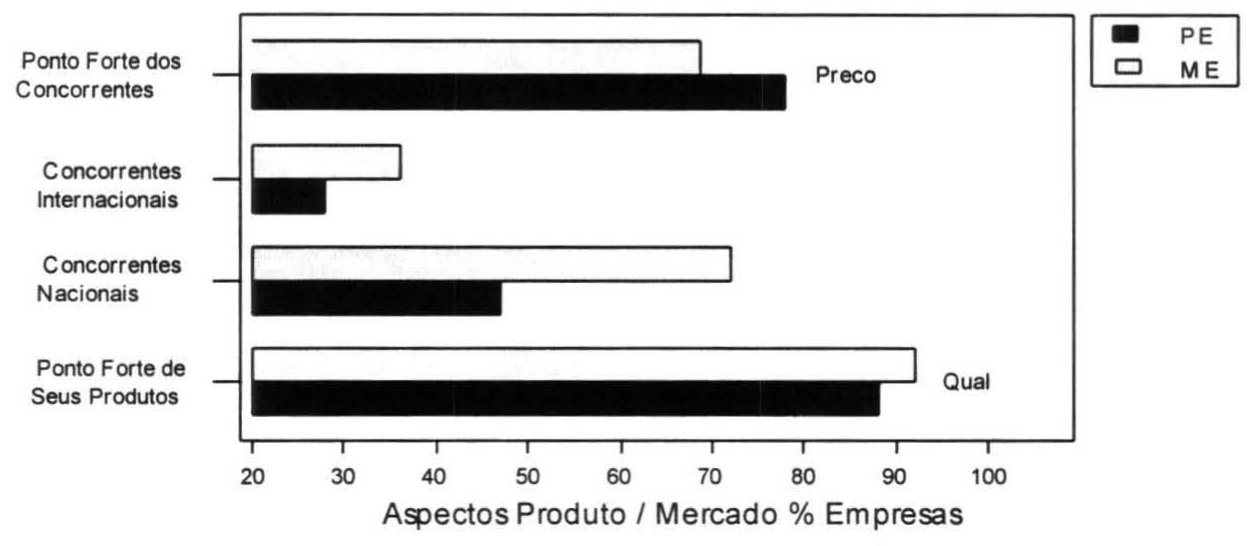

Figura 3 - Aspectos de Produto / Mercado das Empresas

Silva, J. C. T. da, Ferreira, D. - Pequenas e Médias Empresas no Contexto da Gestāo da Qualidade Total 
PRODUÇÃO

da gestão da qualidade, indicam um direcionamento ou não para um planejamento estratégico, tendo como ponto de partida para a introdução de conceitos da filosofia moderna da gestão da qualidade, a liderança do dirigente máximo da organização, pois envolve integração entre as políticas de planejamento da qualidade, de planejamento dos negócios e de autoavaliação organizacional, de acordo com a concepção de Merli (1993).

A pesquisa de campo procurou delinear alguns aspectos desse comportamento, como se pode observar nas Figuras 4 e 5. ocorre com o nível de conhecimento dos funcionários no que refere às metas e objetivos da empresa, concentrados na alta administração para $70 \%$ das empresas, a despeito da confiança da administração nesses funcionários estar situada entre razoável e muito. O gerenciamento por objetivos, de concepção oposta à filosofia da gestão da qualidade total, ainda é praticado em mais de $50 \%$ das PE e em $80 \%$ das $\mathrm{ME}$, significando prática organizacional tipo funcional, dificultando o planejamento e a gestão da qualidade dentro dos conceitos atuais. Por outro lado, os dados indicam que já existe conscientização, nessas empresas, de que a melhoria da qualidade não

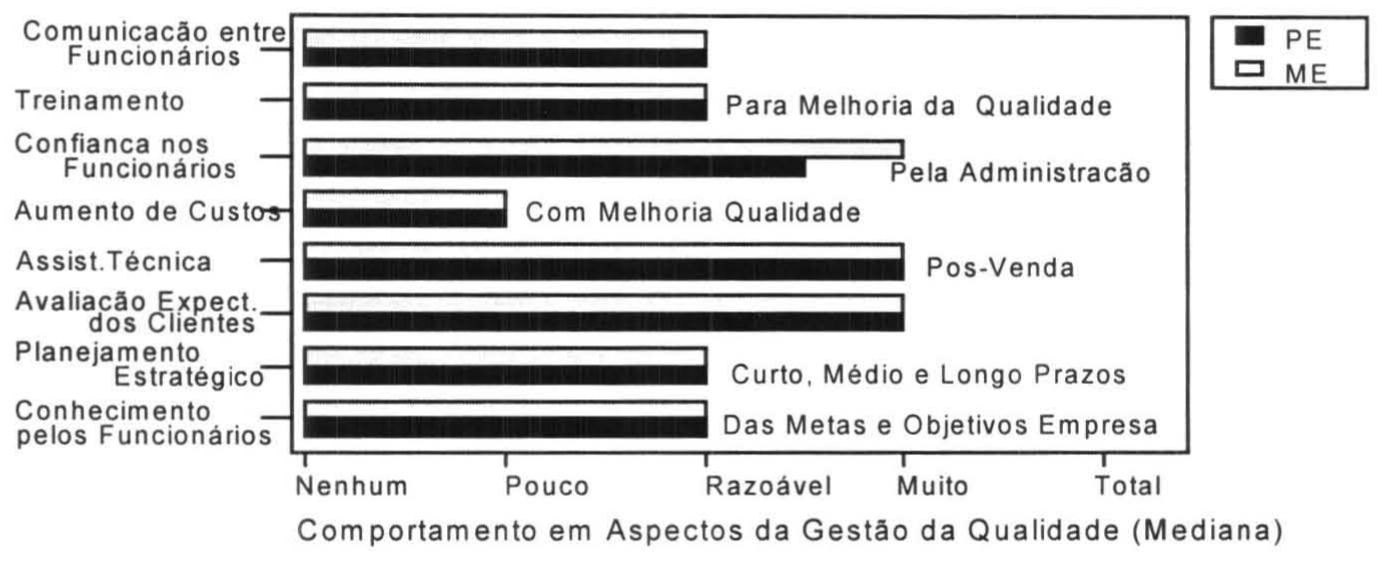

Figura 4 - Comportamento das Empresas em Aspectos da Gestão da Qualidade

De acordo com a Figura 4, o planejamento estratégico global ainda é pouco praticado pelas empresas, com intervalos de confiança $(\mathrm{a}=0,05)$ de comportamento entre pouco e razoável na escala ordinal, e com reduzida possibilidade de integração com o planejamento da qualidade. As PE e ME consideram muito importante a avaliação das expectativas dos clientes e a assistência técnica pós - venda. O treinamento para a qualidade e a comunicação entre funcionários são classificados como razoável, porém, ambos os intervalos de confiança têm indicação de pouco a razoável para a população, significando dificuldades para a gestão da qualidade. $\mathrm{O}$ mesmo significa obrigatoriamente aumento de custos de produção.

A Figura 5 traz indicações de dificuldades das empresas com relação aos conceitos básicos da qualidade. Uma delas é o fato de $60 \%$ das PE e $70 \%$ das ME não praticarem o Controle Estatístico de Processo $C E P$, apesar de que algumas empresas interpretaram erroneamente o CEP como inspeção. Outra indicação de desconhecimento de conceitos nota-se quando as empresas informaram praticar a gestão da qualidade total ( $17 \%$ das PE e de $28 \%$ das ME), com prática simultânea do gerenciamento por objetivos e não prática do controle estatístico de processo. Por último, no campo da 




Figura 5 - Aspectos Gerais da Gestão da Qualidade nas Empresas

garantia da qualidade, constata-se que $33 \%$ das ME e $3 \%$ das $\mathrm{PE}$ já receberam ou estão em fase de certificação pela ISO 9000.

\section{Discussão de Aspectos de Implantação da GQT em PE e ME}

A pesquisa de campo, do setor de manufaturados, forneceu indicações do comportamento dessas organizações em alguns aspectos estratégicos e operacionais da gestão da qualidade. Com base nessas indicações e em conceitos de implantação da Gestão da Qualidade Total, GQT, em organizações de grande porte, sugeridos por alguns pesquisadores como Galgano (1993), Merli (1993) e Shiba (1993), considerando algumas constatações nesse campo citadas por Ghobadian; Gallear (1996) para PMEs, analisaremos alguns aspectos de aplicabilidade para organizações de pequeno e médio porte.

A filosofia da Gestão da Qualidade Total - GQT em organizações teve origem e aplicação em grandes empresas, com metodologias similares mas distintas, cujo embasamento teórico direciona para a busca constante da satisfação do cliente através de um sistema integrado de ferramentas, técnicas e treinamento, envolvendo melhoria contínua dos processos organizacionais, e resultando em produtos e serviços de alta qualidade, com elevada produtividade, agregando nos resultados o valor do trabalho humano. Essa configuração, que deve envolver toda a organização, depende de um aperfeiçoamento contínuo das pessoas e de um planejamento estratégico a curto, médio e longo prazos, ambos em direção a uma forma organizacional alternativa à da teoria taylorista. Praticamente toda essa teoria foi desenvolvida a posteriori da prática dos procedimentos das grandes empresas japonesas nesse campo, procurando delinear o comportamento daquelas organizações. Todavia, muitos aspectos dos procedimentos das empresas japonesas ainda hoje não são conhecidos no ocidente, de acordo com Spear; Bowen (1999) em seu artigo "Decodificando o DNA do Sistema Toyota de Produção", publicado pela Harvard Business Review (September-October 1999). Esse fato, apesar de parecer surpreendente para alguns, na realidade evidencia e confirma a singularidade das organizações, ou seja, que cada organização tem características próprias, quer seja na gestão organizacional, da qualidade, da tecnologia etc. De acordo com a teoria ocidental interpretativa, o sucesso em direção à gestão da 
PRODUÇÃO

qualidade total exige certos pré-requisitos fundamentais,

No que refere à implantação da GQT em organizacomo aqueles citados por Galgano (1993), de acordo com a Figura 6. ções, ainda dentro da concepção de Galgano (1993), deverá haver um compromisso de toda a organização com

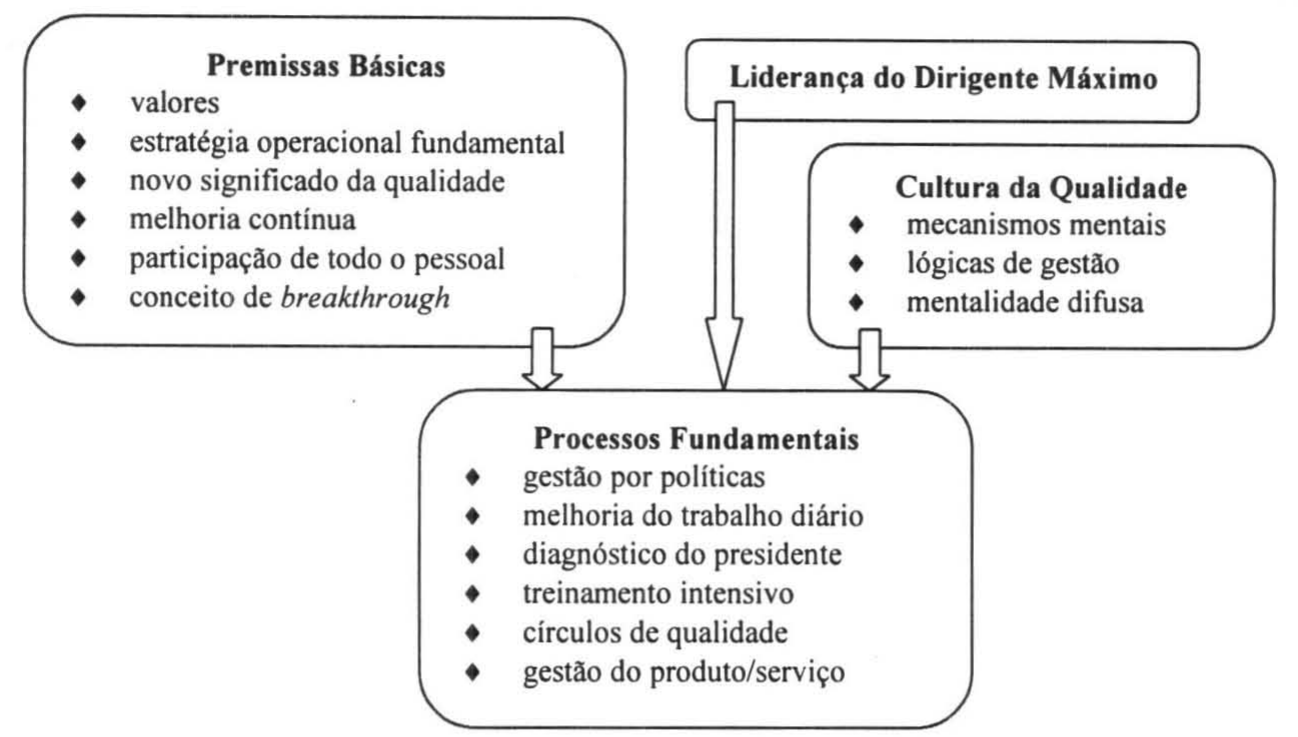

Figura 6- Pré-Requisitos das Organizações para a GQT (Galgano-1993)

Enquanto que as grandes empresas dispõem de mais informação e estrutura para construção e manutenção desses pré-requisitos, os dados da pesquisa de campo indicam dificuldades nesse campo para as PE e ME, onde não são práticas correntes o planejamento estratégico e a formação de cultura para qualidade em toda a organização, levando muitas vezes ao uso de ferramentas e métodos inadequados. Quando na pesquisa de campo indagou-se o ponto forte dos concorrentes, as PE e ME empresas indicaram "o preço", o que significa na realidade que o preço de venda ainda é a principal preocupação dessas organizações, e não a "qualidade" como indicaram. Como na amostra pesquisada existe indicação de estágio organizacional "product-out" nas empresas, de acordo com a classificação Merli (1994), a redução de custos nesse contexto implica principalmente em

"downsizing", resultando em dificuldades dessas organizações a médio e longo prazos para um planejamento direcionado à gestão da qualidade. Nessas organizações de menor porte, a formalização da ISO 9000 poderá colaborar ou não para criar um movimento em direção à qualidade, como acentuou Williams (1997). as estratégias básicas indicadas na Figura 7, onde se constata aspectos relevantes inerentes à essa filosofia. A pesquisa de campo determinou que algumas dessas estratégias não são praticadas pelas $\mathrm{PE} \mathrm{e}$ ME estudadas. A instabilidade de mercado, decorrente da concorrência e de outros fatores externos à empresa, tem trazido dificuldades no relacionamento dessas organizações com seus funcionários, fornecedores e clientes. Existe indicação de que essas organizações de menor porte não conseguem estabelecer uma melhoria contínua de seus processos, pois a ênfase não está no processo e sim na fabricação, sendo muitas vezes a busca da qualidade de conformação seu objetivo final. Quanto à estratégia de desenvolvimento de novos produtos, nem sempre a rapidez, a qualidade, o conhecimento dos consumidores, a confiabilidade e a análise de riscos, estão presentes, como se pode constatar em Silva (1999).

O modelo de implantação da GQT em organizações, Merli (1993), deve estar inserido no Plano Estratégico Global da Empresa, englobando o Modelo de Referência ("Grid") da GQT, o Plano Estratégico Conven 


\section{Estratégias Básicas}

- os clientes como prioridade absoluta

- os colaboradores como recurso estratégico da empresas

- os fornecedores como parte do sistema da empresa

- o processo como fator chave das atividades

- controle de qualidade na gestão empresarial

- melhoria contínua (kaizen)

- rapidez, qualidade e confiabilidade em novos produtos

- contínua ação promocional dos colaboradores

- participação de todos para o êxito da organização

Figura 7 - Estratégias da Organização na Implantação da GQT (Galgano-1993)

cional e a Auto-Avaliação, como fundamentais para o estabelecimento de um Plano Estratégico Plurianual de 3 a 5 anos, onde são estabelecidas as prioridades anuais com metas quantitativas e as metodologias básicas para alcança-las. Os dados da pesquisa de campo indicam que as organizações de menor porte têm limitações para utilizar esse modelo, quer gerenciais ou estruturais. O trabalho de Ghobadian; Gallear (1996) analisou duas pequenas e duas médias empresas da Inglaterra durante a fase de implantação da GQT, onde destacam as vantagens e desvantagem dessas organizações em comparação com as grandes empresas. Sugerem, de acordo com a Figura 8, um modelo de implantação da GQT centralizado na gestão do processo em direção à melhoria contínua, envolvendo o foco nas pessoas, no mercado, no processo, na comunicação e na medição ou avaliação dos resultados. Porém, não aplicaram esse modelo nas empresas estudadas. $\mathrm{Na}$ analise das organizações pesquisadas concluíram que " os conceitos de gestão apropriados para grandes empresas podem não ser apropriados para as PMEs". Também concluíram que: "teoricamente, as variáveis porte da empresa e características da GQT são independentes" ; "são mais significativos o estilo de gestão, o estilo empreendedor, a autoatualização, e o estilo de associação"; e que "o maior obstáculo para a introdução da GQT em PMEs é a realização do gerenciamento". Evidentemente, esses aspectos também devem ser considerados na implementação da GQT em grandes organizações, e fazer parte rotineira de qualquer empresa que queira sobreviver no mercado. $\mathrm{O}$ modelo sugerido por Ghobadian; Gallear (1996) incorpora, em menor escala, o modelo de Shiba (1993), que

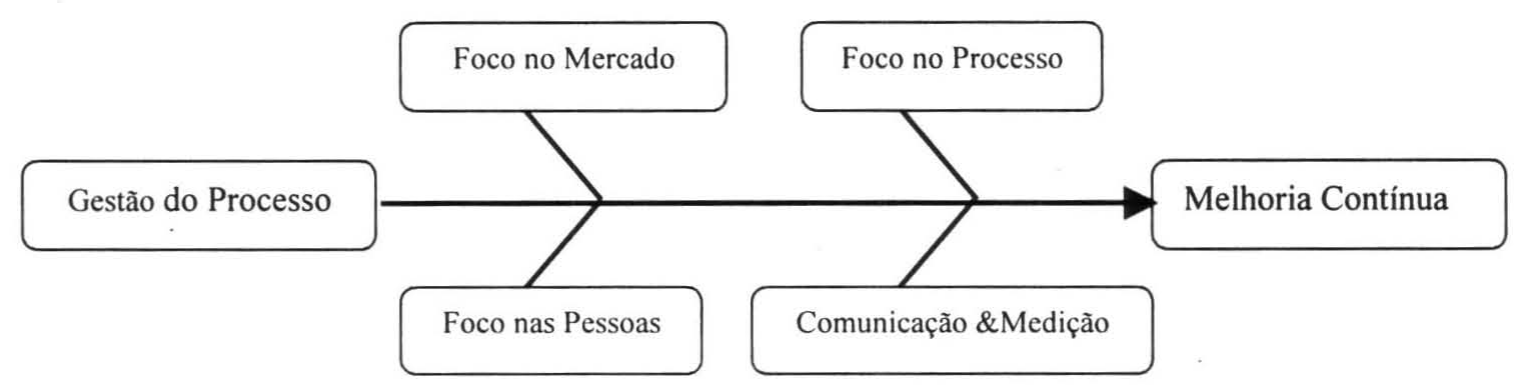

Figura 8 - Implementação da GQT em Pequenas e Médias Empresas; Ghobadian; Gallear (1996) 
PRODUÇÃO

envolve as fases de "orientação" (metas, organização), de "empowerment" (treinamento, promoção, divulgação); e de "alinhamento" (diagnóstico, monitoração, prêmios e incentivos), com a utilização do ciclo PDCA.

Embora o acesso à informação e comunicação seja limitado, nas PMEs, como se pôde constatar na pesquisa de campo, acreditamos que antes de implementar melhorias organizacionais essas organizações devem proceder uma auto-avaliação no campo da qualidade, utilizando por exemplo uma metodologia similar àquela proposta por Conti (1995), ou seja, sentido inverso ao processo. A fase seguinte seria desenvolver uma programação simplificada e específica para essa categoria de organização, incluindo inicialmente o treinamento multidisciplinar de algumas lideranças, e o aproveitamento da flexibilidade, integração, características quase sempre existentes nessa categoria de empresas, onde a distancia funcional entre a alta administração e o "chão de fábrica" é menor em comparação às grandes empresas, além da proximidade do mercado e consumidores.

Segundo Main (1994), a liderança do dirigente máximo e a sobrevivência da organização são os dois fatores que direcionam para o empreendimento da GQT,

exigindo da alta administração das empresas esforços e metas claras, as quais segundo Merli (1993), devem abranger as políticas, estratégias e sistemas de gestão, conforme a Quadro 2. A capacitação gerencial da alta administração pode ser considerada diretamente proporcional à dimensão da empresa, pois quanto maior a organização maior o número de pessoas especializadas na cúpula da organização. Assim, essas empresas têm maior capacitação gerencial para implementar as políticas, estratégias e sistemas de gestão especificadas no Quadro 2, dentro da GQT.

Após o estabelecimento dos planos estratégicos da organização, bem como das políticas, estratégias, sistemas de gestão e direcionamento com procedimentos e métodos, a implantação da GQT exige metodologias e ferramentas básicas para a execução no front, ou seja, no chão de fábrica, de onde realmente sai o produto para o mercado, isto é, o resultado de todos os esforços da organização. Esses métodos operacionais e ferramentas constituem os pontos críticos para implementação efetiva de todo planejamento anterior, exigindo esforços e qualificação do pessoal da organização, tendo em vista a dinâmica e necessidade de continuidade de

\begin{tabular}{|c|c|c|}
\hline Políticas & Estratégias & Sistemas de Gestão \\
\hline * satisfação do cliente & $\begin{array}{l}* \text { planejamento compreensivo } \\
\text { * organização do tempo }\end{array}$ & gestão por política \\
\hline$*$ qualidade em $1^{\circ}$ lugar & $\begin{array}{l}* \text { tempo de desenvolvimento } \\
* \text { gerenciamento manufatura }\end{array}$ & * gestão dia-a-dia \\
\hline * melhoria contínua & $\begin{array}{l}* \quad \text { cadeia de valor do negócio } \\
\text { * comakership }\end{array}$ & * gestão por processo \\
\hline$*$ envolvimento de todos & $\begin{array}{l}* \text { qualidade total } \\
* \text { desdobramento da qualidade } \\
* \quad \text { serviço global }\end{array}$ & gestão inter-funcional \\
\hline
\end{tabular}

Quadro 2 - Políticas, Estratégias e Sistemas de Gestão para a GQT (Merli-1993) 
todas essas operações. A pesquisa de campo indicou o desconhecimento da maioria dessas ferramentas pelas organizações pesquisadas, como as Sete Velhas Ferramentas (folha de verificação; histogramas; análise de Pareto; estratificação; diagrama causa-e-efeito; cartas de controle de processos; diagrama de correlação), sem citar as Sete Novas Ferramentas (diagrama de afinidades; diagrama de relação; diagrama de árvore; diagrama matriz; arvore de decisão; matriz de dados). Por exemplo, o Controle Estatístico de Processo-CEP ainda não é prática para a maioria das organizações pesquisadas do setor de manufaturados.

\section{Conclusões}

Este trabalho analisou a gestão da qualidade em pequenas e médias empresas tradicionais do setor de manufaturados, através de um modelo conceitual simplificado que relaciona alguns aspectos estratégicos e operacionais da moderna gestão da qualidade. A pesquisa de campo e os dados bibliográficos permitiram analisar o comportamento dessas organizações naquele campo, utilizando conceitos correlacionados à teoria e filosofia da gestão da qualidade total. Como sabe, essa teoria foi desenvolvida para o contexto de grandes empresas e muitas dessas organizações, mesmo americanas ou japonesas, ainda não conseguiram incorporar todos seus conceitos.

A aplicação de alguns desses conceitos foi investigada através de pesquisa exploratória, indicando que essas organizações ainda se encontram em uma fase inicial do chamado movimento histórico da qualidade, com maior caracterização para as etapas de inspeção e garantia da qualidade. A concorrência, dentro de uma realidade de mercado peculiar, que envolve, entre outros, aspectos culturais e regionais, ainda não exigiu maior qualidade e produtividade, constituindo ainda o preço como referencial de competitividade. A maior parte das empresas tem grandes limitações no que se refere à gestão da qualidade, pois não praticam planejamento estratégi- co e não fazem uso de ferramentas elementares nesse campo. A produção em pequenos lotes, ou através de plataformas ou padronização, ou mesmo a automatização, têm sido as formas para essas organizações melhorarem um pouco a qualidade de conformação de seus produtos, porém com elevados custos de produção.

Existe indicação de que as dificuldades atuais dessas organizações não são decorrentes da globalização da economia, mas de gerenciamento e de adaptação à uma economia estabilizada, no caso brasileiro, após anos de operação e convivência em uma economia inflacionária. Essa adaptação tem levado muitas empresas a conhecerem pela primeira vez os seus custos fixos e operacionais e, dentro do paradigma da gestão da qualidade, face às dificuldades de mercado, praticam o downsizin, como única alternativa para solução de seus problemas, a curto prazo. A opção por automatização, através de equipamentos e máquinas de produção importadas, em alguns setores poderá resolver problemas de qualidade de conformação e produtividade, a curto prazo, mas não resolverá o problema de gestão organizacional que tem maior dimensão. Com relação aos aspectos de produto/mercado constatou-se que a origem da maior concorrência é do mercado nacional para as $65 \%$ das $\mathrm{PE}$ e $73 \%$ das $\mathrm{ME}$, com o restante advindo da concorrência internacional.

O planejamento estratégico global é pouco praticado nessa categoria de organizações, como também o treinamento de pessoal e comunicação, com o acesso à internet em somente $50 \%$ das ME e $12 \%$ das PE. Por outro lado informaram que têm interesse por estudos organizacionais e consideram importante a avaliação das expectativas dos clientes para com seus produtos e assistência técnica pós-venda. As metas e objetivos da organização ainda são definidos e concentrados na alta administração em $70 \%$ das empresas, ou seja, prevalece a prática organizacional funcional. O gerenciamento por objetivos, prática oposta à filosofia da gestão da qualidade total, ainda é praticado em $50 \%$ das PE e $80 \%$ das ME. Outra constatação relevante é que o controle estatístico de 
PRODUÇÃO processo não é praticado em $60 \%$ das $\mathrm{PE}$ e 70 das $\mathrm{ME}$. Com relação à certificação pela ISO $9000,33 \%$ das ME e $3 \%$ das PE informaram que já receberam ou estão em fase de implantação.

A discussão de implantação da GQT em pequenas e médias empresas demonstrou a dificuldade dessas das organizações se adaptarem à teoria e às práticas de rotina formalizadas e estabelecidas para as grandes empresas, em função da quase inexistência de modelos de referência para essa categoria de organizações. Dessa forma, concluímos pela necessidade de adequação e desenvolvimento de teorias e práticas, procedimentos e metodologias, no campo da gestão da qualidade, específicas para pequenas e médias empresas, tendo como base sua realidade gerencial, organizacional, e características peculiares no que se refere ao mercado regional e às necessidades do consumidor. Um direcionamento nesse campo seria iniciado a partir da prática de alguns conceitos pelo "chão de fábrica" e transplantado posteriormente para outros setores da empresa sempre em função da necessidade e das características peculiares à cada organização, ou seja, similar ao ocorrido nas empresas japonesas nas décadas de 60 e 70, porém com mais facilidades nas condições atuais, tendo em vista a possibilidade de informatização de muitas rotinas. Para este empreendimento faz-se necessário, também que as empresas brasileiras ampliem e qualifiquem adequadamente seu quadro de técnicos de nível médio, fator esse preponderante e muito praticado em empresas japonesas e coreanas. Com a aplicação de uma metodologia e estrutura dessa natureza, as pequenas e médias empresas poderiam aprimorar a gestão organizacional, da qualidade e aspectos essenciais da gestão da tecnologia, como fatores de sobrevivência e de expansão de seus mercados no âmbito nacional e internacional.

\section{Referências Bibliográficas}

BRYMAN, A. Research methods and organization studies. Unwin Hyman, London, 1989.

CONTI, T., Self Assessment and Strategic Inprovement Planing. Seminário em Busca da Excelência. São Paulo, Março/1995. 1956.

CROSBY, P. Quality is free. Mentor, New York,

DODGE, H. ; ROMIG, H. Sampling inspection tables. John Wiley, New York, 1944.

FEIGENBAUM, A. V. Total quality control. Harvard Business Review, 1956.

GALGANO, A., Calidad total. Diaz de Santos S. A.. Madri, 1993

GARVIN, D. A. Gerenciando a qualidade. Quality Mark, Rio de Janeiro, 1992.

GITLOW, A. The Deming guide to quality and competitive position. Printice-Hall, New Jersey, 1987.

GHOBADIAN, A.; GALLEAR, D. N. Total quality management in SMEs. Omega, v. 24, Issue 1, p.83-106, Feb. 1996

HALPIN, J. F. Zero defects. McGraw-Hill, New York, 1956.

HAYES, B. E. Measuring customer satisfaction: development and use of questionaires. ASQC Quality Press, 165p., Wisconsin-USA, 1992.

JURAN, J. Quality control handbook. MacGraw-Hill, New York, 1951.

MAIN, J., Guerras pela qualidade. Campus, Rio de Janeiro, 1994.

MERLI, G. Eurochallenge. Coopers\&Lybrand, London, 1993.

MERLI, G. Comakership. Quality Mark, Trad. Gregório Bouer, Rio de Janeiro, 1994. 
PARKIN, M. A.; PARKIN, R. . Impacto of TQM in UK SMEs. Industrial Management and Data Systems, v. 96, Issue 4, p. 6-10, 1996

RADFORD, G. The control of quality in manufacturing. Ronald Press, N.Iorque, 1922.

SHEWHART, W. A. Economic control of quality of manufactured product. VanNostrange, Nova Iorque, 1931

SHIBA, S., A new american TQM. Productivity Press, Cambridge, 1993.

SILVA, J.C.T. Modelo interativo empresa-universidade no desenvolvimento de produtos. Tese de Doutorado, Escola Politécnica, Depto. de Engenharia de Produção, Universidade de São Paulo. São Paulo, 1999.

SIEGEL, S. Estatística não-paramétrica. São Paulo, McGraw-Hill, 1975.

SPEAR, S.; BOWEN, H. K. Decoding the DNA of the Toyota Production System. Harvard Business Review, September-October 1999, Executive Summary

TAYLOR, F. W. The principles of scientific management. Harper \& Brothers, New York, 1911.

WILLIAMS, N. ISO 9000 as a route to TQM in small to medium sized enterprises : snake or ladder? TQM Magazine, v. 9, Issue 1, p. 8-13, 1997.

\begin{tabular}{|l|l|}
\hline Modec Produtos Metalúrgicos Ltda & Rib. Preto \\
\hline Nauglass Industrial e Mercantil Ltda & Brodowski \\
\hline Estrutel Lençóis Ind.de Estr. Met. Ltda & Lenc. Paulista \\
\hline Construtora Riachuelo Ltda & Botucatú \\
\hline Proteindus Indústria e Comércio Ltda & C. Cesar \\
\hline Refrigerantes Caiçara Ltda & Ourinhos \\
\hline Café Jaguari Ltda & Ourinhos \\
\hline Welcon Indústria Metalúrgica Ltda & Diadema \\
\hline
\end{tabular}

Tabela 1 - Relação das Pequenas e Médias Empresas Consultadas 


\section{ANEXO 1 - PESQUISA DE CAMPO/ RELAÇÃO DAS EMPRESAS}

\begin{tabular}{|c|c|c|c|}
\hline PEQUENAS EMPRESAS & CIDADE-SP & MÉDIAS EMPRESAS & CIDADE-SP \\
\hline Máquinas NPV Ltda. & Valinhos & Plasutil Ind. e Com. de Plásticos Ltda. & Bauru \\
\hline Fazenda Santa Maria & Itapuí & SkolarLtda & Itapui \\
\hline Cerâmica Fantinatti & Ourinhos & Hyster Brasil Ltda. & São Paulo \\
\hline Souza \& Souza Ltda & Bauru & Pillsbury Brasil Ltda & Bauru \\
\hline Engecer - Projetos e Prod. Cerâmicos S.A. & São Carlos & J. Shayeb \& Cia Ltda. & Bauru \\
\hline JPG Compressores Ltda. & Indaiatuba & Ind. de Produtos Alimentícios Cory Ltda. & Rib. Preto \\
\hline PW Hidropeneumática Ltda. & Indaiatuba & Ind. de Compon. Plásticos Incoplas Ltda. & São Carlos \\
\hline Rossi Indústria e Com. de Madeiras Ltda & Bariri & A. W. Faber-Castell S.A. & São Carlos \\
\hline Olaria Vicari Ltda & Bariri & Acumuladores Ajax Ltda. & Bauru \\
\hline João Carlos Bastazini Cia Ltda & Bariri & Ebara Ind. Mecânicas. e Com. Ltda. & Bauru \\
\hline Jevil Ind. e Com. de Art. de Madeira Ltda & Bariri & IndústriaTudor S.P. Baterias Ltda: & Bauru \\
\hline Harba Ind. e Com. Tapetes e Carpetes Ltda & Oscar Bressane & Conexel Con.Elétricas Itda & S.B. Campo \\
\hline Bicovel Bariri Ind.e Com.Óleos Veg. Ltda & Bariri & Taurus Blindagens Ltda & Guarulhos \\
\hline Bariri Ind. e Com. Mármor. Granitos Ltda & Bariri & Mannesmann Dematic Ltda & Cotia \\
\hline Tec Pack de Bariri Embalagens Ltda & Bariri & Ind.de Artef. de Borracha Benfex Ltda & São Paulo \\
\hline Indel Bauru Ind. Eletrometalúrgica Ltda. & Bauru & Mecfil Industrial Ltda & São Paulo \\
\hline Balancer Car do Brasil Ltda. & Bauru & PTI do Brasil SA & São Paulo \\
\hline Godks Ind. Plásticos Ltda & Diadema & Dacarto AS & Osasco \\
\hline Illbruck Industrial Ltda & S. B.Campo & Musta Modas Ltda & Piracicaba \\
\hline Indústria e Comércio de Máquinas Ltda & S. B.Campo & Celpav Celulose e Papel Ltda & Piracicaba \\
\hline Cilinbras Cilindros do Brasil Ltda & Guarulhos & Italbronze Ltda & Guarulhos \\
\hline Indústria, Montag. e Instalações Gimi Ltda & Suzano & Ind. de Artefatos Plásticos Pejon Ltda & São Paulo \\
\hline Poliron Indústria e Comércio Ltda & Diadema & Fiel S/A Móveis e Equip. Industriais & São Paulo \\
\hline Windmoeller \& Hoelscher do Brasil Ltda & Diadema & Cardal Eletro Metalúrgica Ltda & São Paulo \\
\hline Pinna e Cia Ltda & São Paulo & Iódice Ind. e Comércio de Modas Ltda & São Paulo \\
\hline Femaq S/A Fundição Eng. e Máquinas & Piracicaba & Marco Polo Têxtil Ind. e Comércio Ltda & Guarulhos \\
\hline Metalmaxi Metalúrgica Ltda & Piracicaba & Ravel S/A Com. e Industrial Importadora & Diadema \\
\hline Dedini Industrom Transfomadores S/A & Piracicaba & Afa Plásticos Ltda & S. C. do Sul \\
\hline Alutec Indústria e Comércio Ltda & Piracicaba & Cintos e Acessórios Armadilha Ltda & São Paulo \\
\hline Elga Plásticos Ltda. & Laranj.Paulista & Produtos Alimentícios Superbom Ltda & São Paulo \\
\hline Engetécnica Engenharia Com. e Ind. Ltda & Piracicaba & Irmãos Semeraro Ltda & São Paulo \\
\hline Elring Klinger do Brasil Ltda & Piracicaba & JP Indústria Farmacêutica S/A & Rib. Preto \\
\hline BMD Ferramentas Ltda & Charqueada & Intelli Indúst. de Terminais Elétr. Ltda & Orlandia \\
\hline Irmãos Bellotto CIA Ltda & Laranj. Paulista & Cicopal S/A & Rib. Preto \\
\hline Ind. e Com. de Móveis Iracema Ltda & Iracemápolis & Glicolabor Indústria Farmacêutica Ltda & Rib. Preto \\
\hline Fábrica de Maquinas Famasa Ltda & São Paulo & Hidroplás S/A & Botucatu \\
\hline Moretto Ind. e Com. de Madeiras Ltda & Lenç. Paulista & Máquinas Suzuki S/A & S. C. R. Pardo \\
\hline Novatração Artefatos de Borracha S/A & São Paulo & Staroup S/A Indústria de Roupas & Botucatu \\
\hline Probjeto S/A Produtos e Objetos Projetados & São Paulo & Cia Americana Industrial de Ônibus & Botucatu \\
\hline Zeloso Indústria e Comércio Ltda & São Paulo & Refrescos Ipiranga S/A & \multirow[t]{3}{*}{ Rib.Preto } \\
\hline Ibram Ind. Brasileira de Máquinas Ltda & São Paulo & & \\
\hline Basequímica Produtos Químicos Ltda & Rib. Preto & & \\
\hline
\end{tabular}

